\title{
Bracket for attaching the Kowa fundus camera to the Haag-Streit 900 slit lamp
}

\author{
D. H. BRENNAN, T. J. G. PRIGE, AND J. A. TURNBULL \\ Farnborough, Hants
}

A bracket has been designed to allow a Kowa RG II fundus camera to be mounted firmly on a Haag-Streit 900 slit lamp. The bracket provides a steady support which is of particular importance in fluorescein fundus angiography.

The bracket consists of two parts. The upper part of mild steel and finished in satin chrome fits into the camera shoe and can be locked into place. The lower part is black anodised aluminium alloy and replaces the tonometer guide plate. The halves of the bracket mate together and permit rotation and locking by means of a friction clamp (Figs I and 2). A further modification enables the bracket to be attached to a Nikon slit lamp.

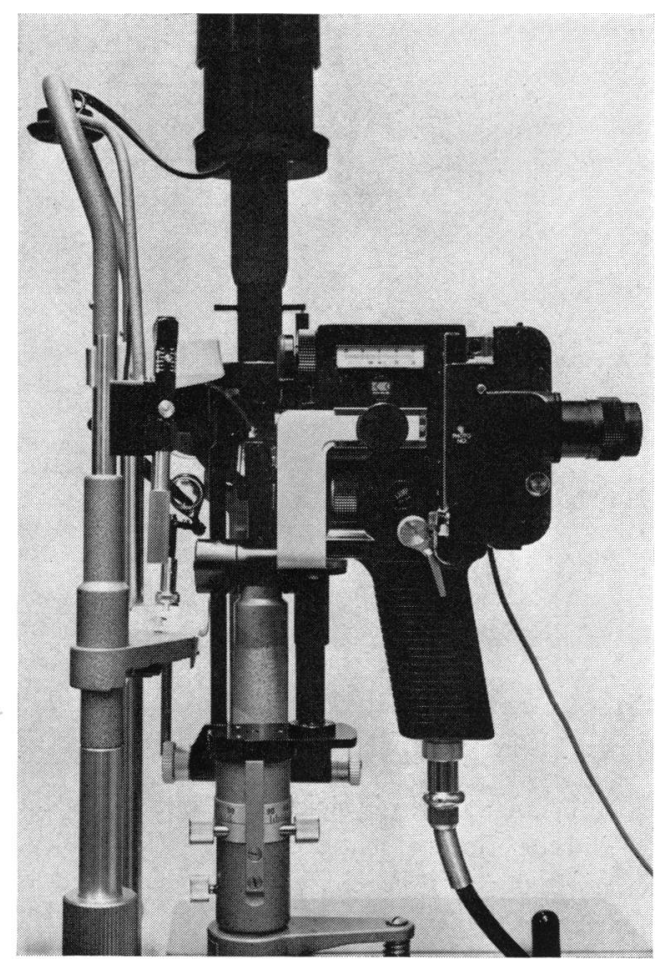

FIG. I Photograph of camera and slit lamp with head support

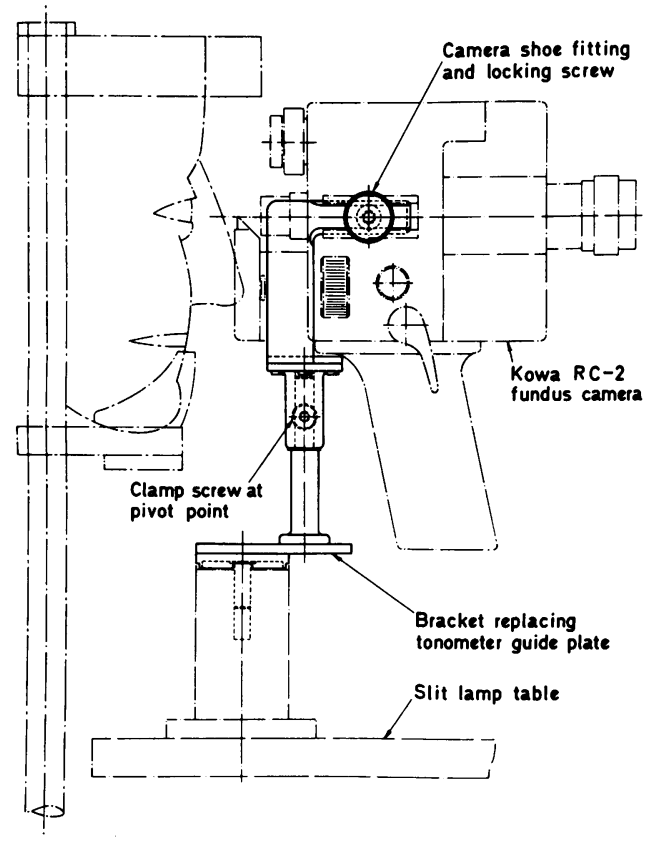

FIG. 2 Diagram of apparatus in use

The limbs of the slit lamp are swung to the side and the bracket and camera placed in position. All adjustments of camera to the eye are made with the normal slit lamp controls except rotary movements which utilize the friction clamp of the bracket.

Received for publication April 2, 1973

Address for reprints: Dr. D. H. Brennan, Royal Air Force Institute of Aviation Medicine, Farnborough, Hants, England The prototypes were made by Mr. Richard Walker of this Institute. 